\title{
DE ENUNCIACIÓN A MODALIDAD: EL CASO DE DE VERDAD
}

\author{
FROM ENUNCIATION TO MODALITY: THE CASE OF DE VERDAD
}

\author{
María Soledad Padilla Herrada \\ Universidad de Sevilla \\ mspadilla@us.es
}

Recibido: 19/06/2019

Aceptado: 14/10/2019

\begin{abstract}
Resumen
En este trabajo centramos nuestro interés en el análisis del marcador de verdad. Trataremos de mostrar que, además de su uso ya asumido como operador que pone de manifiesto el compromiso enunciativo del locutor, también presenta usos en el español actual en los que actúa en el plano modal. Especialmente, nos centramos en los contextos en que puede constituir un enunciado reactivo independiente, en cuyo caso expresa confirmación. Nuestro objetivo es describir sus valores pragmáticos específicos como operador de confirmación dentro de este paradigma (desde luego, por supuesto, claro...) y nos planteamos su posible fijación.

Para llevar a cabo nuestro análisis partimos de un enfoque macrosintáctico desarrollado a través de una metodología pragmática (Fuentes Rodríguez 2013, 2017). Para ello, nos basamos en las muestras de discurso mediado tecnológicamente que se recogen en el Corpus MEsA. Además, nos serviremos de los resultados que ofrecen los corpus Val.Es.Co. 2.0., CREA, CORDE y CORPES XXI.

PALABRAS CLAVE: macrosintaxis; operador discursivo; discurso digital.
\end{abstract}

\begin{abstract}
This research is focused on the analysis of de verdad as a discursive marker. I will try to show its use already assumed as an operator that highlights the enunciative commitment of the speaker and its uses in the current Spanish where it acts in the modal plane. Especially, the analysis is focused on the contexts where it may constitute an independent reactive statement expressing confirmation The objective is to describe the pragmatic values which it adds as a confirmation operator and to consider its possible fixation.

To carry out the analysis, the paper starts with a macrosyntactic approach developed through a pragmatic methodology (Fuentes Rodríguez 2013, 2017). The methodology relies mainly on the samples of technologically mediated communication which are collected from the Corpus MEsA. In addition, I will use the results offered by the corpus Val.Es.Co. 2.0., CREA, CORDE and CORPES XXI.

KEY WORDS: macrosyntax; discursive operator; digital discourse.
\end{abstract}

Para citar este artículo / To cite this article: Padilla Herrada, Soledad (2019): "De enunciación a modalidad: el caso de de verdad". González Sanz, Marina y Pérez Béjar, Víctor (eds.): ELUA: Macrosintaxis en construcción, Anexo VI, págs. 53-72.

Enlace/Link: http://dx.doi.org/10.14198/ELUA2019.ANEXO6.04 


\section{INTRODUCCIÓN}

En el español coloquial actual encontramos diversas expresiones que desempeñan una función macrosintáctica (Blanche-Benveniste 2002, 2003; Berrendoner 2002, 2003; Fuentes Rodríguez 2017) relacionada con los agentes comunicativos. El estudio de estas formas, muchas de ellas aún no plenamente fijadas, es una tarea en la que aún queda mucho por hacer. Aunque, ciertamente, son muchos los trabajos centrados en la gramaticalización de marcadores del discurso, no es tan usual encontrar trabajos en los que se describan operadores en proceso de fijación, si bien es cierto que contamos con trabajos recientes en esta línea (Fuentes Rodríguez 2012, 2016; Lanero Rodríguez 2018, Brenes Peña 2018, González Sanz 2017).

Para contribuir a la investigación de estas unidades, en este trabajo, centramos nuestra atención en uno de los usos actuales de la expresión de verdad. Además de sus empleos ya recogidos en la bibliografía como operador que pone de manifiesto el compromiso enunciativo del locutor ante lo dicho, o como pregunta o respuesta confirmativa (Fuentes 2009, Santos Río 2003), presenta otros usos en la interacción coloquial. En ellos, el valor enunciativo parece unirse al modal, lo que exige una reflexión sobre su ámbito de acción.

Nuestro objetivo es realizar un análisis global de esta forma y recoger no solo los usos ya descritos en la bibliografía especializada sobre marcadores (Santos Río 2003, Briz, Pons y Portolés 2008 y Fuentes Rodríguez 2009), en los que esta expresión suele describirse como operador enunciativo, sino incluir usos documentados del español coloquial actual en los que de verdad ocupa el hueco funcional de un operador de modalidad confirmativa y constituye un enunciado reactivo independiente. Para ello, partimos de los datos que nos facilita el Corpus MeSA, el corpus de conversaciones Val.Es.Co. 2.0. y los corpus de la RAE: CORDE, CREA y CORPES XXI.

En primer lugar, nos ocuparemos de exponer las bases conceptuales de nuestro marco teórico y los corpus empleados. También daremos cuenta de la rentabilidad del núcleo verdad en la formación de marcadores del discurso. A continuación, nos centraremos en los distintos usos que presenta esta construcción en nuestro corpus y nos detendremos, especialmente, en el empleo de de verdad como intervención reactiva de confirmación. Por último, presentaremos nuestras conclusiones.

\section{MARCO METODOLÓGICO}

Cuando analizamos la lengua como instrumento real de comunicación, observamos múltiples expresiones cuyo estudio no puede llevarse a cabo a través de la microsintaxis o sintaxis de la oración, ya que esta no nos proporciona herramientas suficientes para dar cuenta de la complejidad que entrañan. En nuestro caso, para llevar a cabo el análisis de de verdad y dar cuenta de su multidimensionalidad, adoptamos un enfoque macrosintáctico (Fuentes Rodríguez 2013, 2017), desarrollado a través del modelo de Lingüística Pragmática de Fuentes Rodríguez (2000).

Desde este marco metodológico, promovemos una gramática que parte de la realización discursiva y que considera como unidad básica de análisis el enunciado, definido como la unidad mínima de comunicación. El texto conversacional, del que partimos en este trabajo, se organiza en torno a intercambios compuestos por intervenciones (Val.Es.Co. 2014). Cada 
una de estas intervenciones puede estar compuesta, desde nuestra perspectiva, por uno o varios enunciados ${ }^{2}$.

El enunciado es la unidad básica de la macrosintaxis, la cual estudia construcciones que solo aparecen en el discurso realizado, pero sin abandonar la visión componencial propia de la microsintaxis o sintaxis de la oración. Consideramos, por tanto, que en las unidades superiores a la oración también existe una determinada organización y una serie de funciones desempeñadas por paradigmas de unidades específicas: los operadores ${ }^{3}$ (Fuentes Rodríguez 2017), que actúan en el enunciado, ocupando determinados huecos funcionales de la macroestructura, pero externos a la rección verbal. No obstante, como mostraremos en este trabajo, estos huecos funcionales también pueden estar ocupados por expresiones que desempeñan una función análoga.

Teniendo en cuenta que partimos de un corpus conversacional para realizar nuestra investigación, también tomamos como referencia teórica las investigaciones de Briz (1998) y Narbona $(2000,2015)$ en nuestra caracterización de la conversación coloquial y del grupo Val.Es.Co. (2014) en la definición de las unidades de la conversación intervención ${ }^{4}$ e intercambio $^{5}$.

\section{CORPUS}

Para realizar nuestro análisis de los usos actuales de la expresión de verdad nos basamos en los intercambios comunicativos recogidos en el Corpus MEs $A^{6}$. Dicho corpus está compuesto por diferentes muestras de discurso digital procedente de diversas redes sociales y plataformas virtuales. A saber: blogs, foros digitales, páginas web de temática diversa, Facebook, Twitter, Instagram, WhatsApp y Youtube ${ }^{7}$.

Este corpus se propone recoger material lingüístico que sirva como una representación del discurso digital empleado a diario por millones de usuarios en todo el mundo. Un corpus como este es muy útil en nuestra investigación, ya que en él encontramos múltiples contextos que nos permiten documentar usos lingüísticos que se emplean en el español más actual. Además, la naturaleza de este tipo de comunicación nos permite acceder a datos documentados muy recientemente. En este corpus se recoge discurso datado entre 2007 hasta la actualidad ${ }^{8}$.

En estos medios, la comunicación se desarrolla, mayormente, a través del código gráfico y el registro predominante es el coloquial. De hecho, el discurso que encontramos en el corpus puede describirse partiendo de los rasgos fundamentales de la conversación coloquial que marca Briz (1998: 40): suele haber una escasa planificación, la toma de turno no

2 Conviene recordar que, en función de los distintos modelos de segmentación del discurso existentes y de sus objetivos, la unidad discursiva mínima considerada no siempre es el enunciado. Por ejemplo, el grupo Val.Es.Co. (2014) parte de la unidad acto.

3 En Fuentes Rodríguez (2009) encontramos un inventario de estas unidades.

4 Intervención como la "unidad monológica máxima" (Val.Es.Co. 2014: 14).

5 "Dos intervenciones sucesivas de distintos emisores, una de inicio y otra de reacción, constituyen la mínima unidad dialógica estructural: el intercambio" (Val.Es.Co. 2014: 23).

6 Este corpus fue uno de los objetivos del proyecto de excelencia del Ministerio de economía y competitividad "Macrosintaxis del español actual: estructura y relaciones" dirigido por la Dra. Catalina Fuentes Rodríguez.

7 Para más información, véase la Guía del Corpus MEsA, disponible en línea.

8 Es un corpus que aún continúa elaborándose $\mathrm{y}$, semanalmente, se introducen nuevos materiales. 
predeterminada, temática no especializada, relación de igualdad entre los interlocutores, relación vivencial de proximidad ${ }^{9}$, tono informal, etc. Sin embargo, el hecho de que la conversación generada en estos medios se lleve a cabo en ausencia y a través del código gráfico, hace que presente unos rasgos específicos de este tipo de discurso. Por ejemplo, la ausencia de rasgos suprasegmentales hace que los usuarios traten de reponer información a partir del empleo de emoticonos y otros recursos multimodales (Yus 2001, 2010, 2011). Con todo, podemos decir que, en general, los rasgos de este tipo de discurso se encuentran más cercanos a la inmediatez, empleando los términos de Koch y Oesterreicher $(2007)^{10}$.

Además del Corpus MEsA, nos servimos de los resultados que nos proporciona el Corpus Val.Es.Co. 2.0., para verificar si estos usos de de verdad se documentan también en la conversación coloquial prototípica. Asimismo, para completar los resultados aportados por estos corpus conversacionales y tratar de registrar los usos más tempranos de esta expresión, atendemos a la información que nos aportan los corpus de la Real Academia Española: el Corpus diacrónico del español (CORDE), el Corpus de referencia del español actual (CREA) y el Corpus del español del siglo XXI (Corpes XXI).

\section{LA CREACIÓN DE NUEVAS EXPRESIONES DE CONFIRMACIÓN}

Como ya hemos indicado, desde nuestra perspectiva macrosintáctica, concebimos que en la estructura del enunciado existen determinados huecos funcionales ocupados por un paradigma de unidades específicas: los operadores. En el caso de la confirmación ${ }^{11}$, nos referimos a unidades como: por supuesto, claro, sin duda, etc.

En los intercambios recogidos en el Corpus MEsA hemos podido comprobar cómo estos huecos funcionales, además de estar ocupados por los operadores, pueden estar ocupados por otras expresiones, aún no fijadas, que desempeñan funciones análogas a las de un operador y que germinan para satisfacer las necesidades de los hablantes, tales como: dímelo a mí, eso digo yo, cómo lo sabes o de verdad, expresión de la que aquí nos ocupamos. Como podemos ver, desde un punto de vista composicional, estas formas son muy heterogéneas. En todos los casos se trata de construcciones que tienen su origen en unidades de la microestructura (oraciones o sintagmas de distinto tipo) que pasan a desempeñar una función macroestructural en contextos dialógicos reactivos. En esta posición, pueden llegar a gramaticalizarse hasta constituir un nuevo operador, siempre que cumplan determinados rasgos relacionados con este proceso (Traugott 1995, 2003, Company 2004), tales como presentar un contenido semántico procedimental, la fijación morfológica y sintáctica (no permitir la alteración del orden de los elementos que lo componen, no admitir elementos intercalados), constituir un grupo entonativo independiente, poder combinarse con otras unidades fijadas, entre otras.

9 Aunque, en muchos casos, esta relación de proximidad no existe, los usuarios, protegidos por su identidad virtual, simulan dicha cercanía, lo cual, en múltiples ocasiones, genera descortesía en el discurso de estos medios (Brown y Levinson 1987).

10 Traducción al español de Araceli López Serena.

11 En Padilla Herrada (2017) se describen algunas expresiones de confirmación registradas en WhatsApp. 


\section{RENTABILIDAD DEL NÚCLEO VERDAD EN LA FORMACIÓN DE MARCA- DORES DISCURSIVOS}

Antes de adentrarnos en el análisis de de verdad, nos parece oportuno poner de manifiesto la alta frecuencia en la que verdad ${ }^{12}$ aparece como núcleo de un marcador o partícula discursiva, lo cual da cuenta de su rendimiento en la formación de estas unidades. Si buscamos en algunas de las obras de referencia sobre marcadores y partículas discursivas en español (Santos Río 2003, Briz, Pons y Portolés 2008 y Fuentes Rodríguez 2009) encontramos, además de de verdad, los siguientes marcadores:

- $\quad$ A decir verdad (Santos Río 2003, DPDE 2008, Fuentes Rodríguez 2009)

- $\quad$ En verdad (Santos Río 2003)

- $\quad$ La verdad (Santos Río 2003, DPDE 2008, Fuentes Rodríguez 2009) ${ }^{13}$

- $\quad$ La verdad sea dicha (Santos Río 2003, Fuentes Rodríguez 2009)

- En honor a la verdad (Santos Río 2003, Fuentes Rodríguez 2009)

- A la verdad (Santos Río 2003)

- La verdad ante todo (Santos Río 2003)

- $\quad$ La verdad es que... (Santos Río 2003, DPDE 2008)

Comprobamos, a partir de este breve compendio, que en la bibliografía encontramos varias formas con la base verdad y que todas ellas actúan en el plano enunciativo. Esto puede explicarse porque, tal y como señala Fuentes Rodríguez (2012: 136), “el concepto de verdad está ligado al decir y está lingüísticamente omnipresente, lo cual hace que se genere un universo lingüístico-cognitivo en el que se van reproduciendo funciones y valores". Como señala esta misma autora, (Fuentes Rodríguez 1995: 70), los marcadores relacionados con a la concepción de verdad no pierden la relación con su referencia primaria, o marco cognitivo primero, sino que este se emplea como sustrato que actúa a nivel secundario. Todas estas formas, por tanto, están relacionadas con la noción de verdad y a través de su semántica evocan los conceptos de realidad, certeza, veracidad, convicción, etc. Sin embargo, la construcción sintagmática y las funciones varían. A continuación, profundizamos en el análisis de una de ellas: la forma de verdad.

\section{ANÁLISIS DE DE VERDAD}

En este apartado daremos cuenta, en primer lugar, del empleo de de verdad como construcción libre. A continuación, mostraremos otros usos derivados de este, en los que esta forma actúa en relación a los ámbitos macroestructurales de la enunciación y la modalidad. Tras explicar y ejemplificar las distintas funciones que desempeña en nuestro corpus, nos centraremos en el uso de de verdad como enunciado reactivo independiente, en cuya posición funciona de manera equivalente a un operador modal de confirmación.

12 Para un análisis de la rentabilidad que tienen algunas expresiones surgidas a partir de verdad en el discurso político, véase Fuentes Rodríguez (2012).

13 También Serrano (1997) analiza esta forma. 


\subsection{De verdad como construcción libre}

Desde un punto de vista microsintáctico, de verdad es una construcción que se enmarca en la sintaxis oracional y se integra entonativamente en el enunciado. Composicionalmente, está formada por un sintagma nominal con preposición y presenta un contenido semántico designativo, que es el resultado de la suma del significado de cada uno de los miembros que la conforman. Cuando presenta este uso, funciona en el discurso de un modo similar al adjetivo verdadero. Lo vemos en los ejemplos siguientes del Corpus MeSA:

(1) Usuario 91 (mujer) $)^{14}$ :

Ya ves tu lo que me importa a mí ser ruin y cruel con un subnormal. Detrás de bromas crueles siempre hay algo de verdad. Por cierto, las palabras Puta, Panchita...ect no me parecen a mi una broma, si esas son tus bromas, deberías acudir a un psiquiatra inmediatamente. A ver si aprendemos.

(Youtube, Corpus MeSA)

(2) Usuario 137 (no identificado):

Perdón q como no soy muy dada ha estás cosas he dado sin querer....como decía a la gente q como yo no somos muy seguidores de nada pero tú has hecho q gente como yo lo seamos ñ. Enhorabuena por tú Familia, Enhorabuena por tú mujer ( sois un ejemplo y una gran ayuda) Enhorabuena por tus seguidores, Enhorabuena por un largo etcétera y sobretodo ENHORABUENA POR SER DE VERDAD. MIL GRACIAS@dulceida. videos@dulceida

(Instagram, Corpus $\mathrm{MeSA}$ )

A partir de este uso como construcción libre, se ha ido extendiendo el ámbito de la expresión, dando lugar a otros usos referidos a la esfera del hablante. Estos usos derivados la sitúan en el marco de la macroestructura (Fuentes Rodríguez 2017) y han surgido a través de un proceso de subjetivización (Company 2004) que ha hecho que de verdad salte del ámbito referencial al interpersonal. Estos nuevos empleos interactivos están relacionados con los planos enunciativo y modal, fundamentalmente, ya que esta construcción pasa a manifestar la subjetividad del hablante, que se implica en el discurso emitido. Configura, así, un caso de lo que Dostie (2004) denomina pragmaticalización, dado que esta estructura, en determinados usos que presentamos a continuación, no se emplea con su significado designativo, sino que presenta un contenido procedimental.

\subsection{De verdad como complemento periférico: [te] lo digo de verdad}

Uno de los usos frecuentes en nuestro corpus es la expresión de verdad antecedida por el verbo dicendi y en ocasiones por la referencia al receptor que se materializa en el pronombre personal de complemento indirecto. En estos casos, funciona como un complemento periférico referido a la enunciación. Es decir, pertenece a lo que Fuentes Rodríguez (2007) denomina periferia II. Frente a otros complementos periféricos, como los circunstantes o los complementos de reinterpretación restrictiva, esta expresión actúa en el nivel macroes-

14 En el Corpus MeSA censuramos la identidad de los hablantes. Solo damos cuenta del sexo: hombre, mujer o no identificado. 
tructural de la enunciación y se sitúa en posición periférica, separado por pausas del resto del enunciado, al que afecta en su totalidad. Mediante el empleo de esta forma, el hablante expone su intención de ser sincero, veraz, lo cual tiene como consecuencia un efecto de ponderación de lo dicho, una manifestación expresa del compromiso del hablante ante lo enunciado. Puede aparecer al principio o al final del enunciado al que afecta. Ahora bien, se trata de una expresión que no presenta un grado avanzado de fijación, ya que admite la variación del orden de los elementos que lo componen (de verdad [te] lo digo) y presenta variación morfológica en el pronombre personal de complemento indirecto:

(3)@usuarioanónimo:

Mira os lo digo de verdad estoy del frío calor frío calor hasta los huevos, se me corta el puto cuerpo

(Twitter, Corpus MeSA)

Como vemos en este ejemplo, la construcción, situada en el margen izquierdo, aparece con el pronombre personal de CI en su forma de segunda persona del plural, seleccionando como alocutario a todos los seguidores en la red social del locutor. Aquí, aparece introducida por el enfocador de la alteridad mira $^{15}$. En otras ocasiones, podemos encontrar esta expresión introducida por el pronombre personal de CI en segunda persona del singular, como en el siguiente caso, en el que aparece en el margen derecho del enunciado:

(4)@usuarioanónimo:

Qué hijos de puta son, te lo digo de verdad. Nunca entenderé cómo la gente se puede aprovechar de los más necesitados sabiendo cómo están y sin que la conciencia les remuerda... Pero ya se encargará la vida de poner a cada uno en su lugar.

(Twitter, Corpus MeSA)

También encontramos casos en los que el complemento periférico aparece sin seleccionar expresamente al receptor a través de ningún pronombre personal:

(5)@usuarioanónimo:

Hasta la poyisima de juego de tronos lo digo de verdad

(Twitter, Corpus MeSA)

En el siguiente ejemplo, aunque no es algo común en nuestro corpus, hemos encontrado este complemento periférico combinado con un operador enunciativo: sinceramente. Se trata, por tanto, de la coordinación de dos elementos semejantes en el margen izquierdo del enunciado. Mediante la combinación de estos elementos, el hablante hace hincapié en su compromiso con lo dicho, en su intencionalidad de aludir a la "verdad" y de ser sincero:

(6) @usuarioanónimo:

Sinceramente y lo digo de verdad, cuando salga nominado Kiko Rivera deberíamos ir los fans de todos los demás a por él. Me da igual quién gane esto pero no me da la gana que gane él cuando encima es un coñazo de concursante e Irene directamente es un mueble.

15 Este elemento desempeña una función fática interna ya que llaman la atención al receptor acerca de la importancia del segmento del enunciado inmediatamente posterior (Pons Bordería 1998). 
\#GHDÚOLímite3

(Twitter, Corpus MeSA)

\subsection{De verdad como operador enunciativo}

Su empleo como operador enunciativo constituye un paso más en el proceso de fijación de esta construcción. Este uso sí aparece descrito en la bibliografía especializada ${ }^{16}$ (Santos Río $2003^{17}$ y Fuentes Rodríguez $2009^{18}$ ). Como operador enunciativo, de verdad afecta a todo el enunciado en el que se inserta. Se emplea, por tanto, como reforzador del acto de decir, mediante el que el locutor manifiesta su intencionalidad de decir la verdad, de ser sincero en su alocución y, por tanto, su compromiso asertivo. Por tanto, acentúa, a su vez, la fuerza ilocutiva del enunciado. Puede aparecer en posición inicial, intercalada o final, separado entonativamente del contenido proposicional, como vemos en los ejemplos 7, 8 y 9 , respectivamente.

(7) De verdad, valorar a vuestros amigos, no sabéis lo horrible que es no tenerlos, estar sola siempre, nunca tener planes, buscar escusas absurdas continuamente para que tus padres no piensen que eres una puta fracasada y que no sales porque no quieres, lo odio.

(Blog, Corpus MeSA)

(8) Hola, esta tortilla de patatas, de verdad, deliciosa!

(Blog, Corpus MeSA)

(9) Usuario 15 (mujer):

[mención a usuario] eres un embustero eso no es verdad los catalanes no hacemos eso, de verdad.

(Youtube, Corpus MEsA)

De verdad también se usa como enunciado interrogativo, en cuyo caso constituye una expresión de petición de confirmación de lo que el interlocutor acaba de decir (Santos Río 2003, Fuentes Rodríguez 2009). Puede aparecer como marcador que introduce un enunciado interrogativo directo, como en el siguiente caso:

(10) Usuario 15 (mujer):

¿De verdad estás negando que a las mujeres se les responsabiliza de las tareas domésticas?

(Foros, Corpus MeSA)

O constituir una pregunta confirmativa:

(11) Espera ¿Marion Cotillard lo hizo bien? ¿De verdad?

[https://www.youtube.com/watch?v=7PWJD_uCkK8]

(Blog, Corpus MeSA)

16 No aparece en el DPDE (Briz, Pons y Portolés 2008).

17 Según este autor, se usa para reforzar, por vía realizativa, un aserto.

18 Fuentes Rodríguez (2009) lo define como un modificador de la enunciación mediante el que el hablante indica que dice la verdad. 
En estos últimos ejemplos, vemos que la construcción empieza a derivar hacia un uso modal. Esto se manifiesta en que expresa un valor de duda. Además, en estos casos, las preguntas confirmativas con de verdad manifiestan el desacuerdo del locutor ante lo dicho previamente por el interlocutor.

Por otra parte, como señala Fuentes Rodríguez (2009), de verdad también puede aparecer como respuesta a una pregunta confirmativa:

(12) CARMEN

¿De verdad que antes te dedicabas a la política?

LOLA

De verdad.

(Corpes XXI, 2001) $)^{19}$

\subsection{De verdad como operador de intensificación}

También hemos encontrado en nuestro corpus un uso de de verdad con una función de intensificador ${ }^{20}$ de un segmento del enunciado. Aparece, normalmente, en posición antepuesta al fragmento al que afecta e integrado en su mismo grupo entonativo. Es decir, en este uso, no presenta marginalidad sintáctica. Sin embargo, a pesar de estar integrado en la proposición, presenta un contenido procedimental. Por tanto, en este uso, funciona de un modo similar a otros operadores que presentan un efecto intensificador como complemente, totalmente o absolutamente. Estos adverbios, como destaca Fuentes Rodríguez (2007: 15), pueden funcionar como expresiones de confirmación en respuesta, lo cual, como veremos, también sucede con de verdad.

En este empleo, nuestra unidad actúa en el plano modal-enunciativo al marcar al hablante como locutor y enunciador de lo dicho. También actúa en el plano informativo, ya que enfatiza informativamente el segmento al que afecta, así como en el plano argumentativo (Anscombre y Ducrot 1983). En los siguientes ejemplos vemos que puede afectar a adjetivos positivos y negativos:

(13) [enlace al vídeo "estrategias para emprender un negocio, por Daniel Marcos"] ${ }^{21}$ [...] Daniel de verdad es buenísimo en todo lo que tenga que ver con emprendimiento y hacer empresas crecer. Yo he aprendido mucho de sus cursos y creo que si están por poner un negocio les conviene echar un ojo.

(Blog, Corpus MeSA)

(14) Usuario 23 (hombre):

Decepción total no puedo creer que se haya salido antes que Miri Nathan y Silene. Es de verdad INJUSTO ellos no merecen estar ahí sobre todo Nathan. :-8)

(Facebook, Corpus MeSA)

19 Fragmento perteneciente a Sin noticias de Dios de Agustín Díaz Yanes.

20 Rodríguez Ramalle (2003) y Fuentes Rodríguez (2008) analizan la función intensificadora de diversos adverbios como terriblemente, extraordinariamente, horrorosamente, inmensamente, etc.

21 En el Corpus MESA se ofrece información adicional del recopilador que pueden ser relevante para el investigador. 
Como vemos en estos casos, de verdad expresa intensificación de la cualidad positiva o negativa a la que afecta, al mismo tiempo que presenta un contenido evaluativo en el que se valora lo dicho como verdadero. La enfatización que provoca nuestra construcción desencadena también un valor de intensificación del contenido que tiene un efecto en el plano argumentativo al expresar rotundidad. De este modo, es equiparable al adverbio verdaderamente.

En estos ejemplos, además, de verdad se sitúa en posición antepuesta al adjetivo, con lo cual se presenta como un mecanismo de focalización informativa (Fuentes Rodríguez 2006) que potencia aún más su fuerza. Aunque esta forma aparezca aquí como intensificador de adjetivos, no se trata exactamente de una intensificación de cualidad, sino que se trata de una intensificación resultante del énfasis enunciativo de la construcción. Se trata, así, de una intensificación enunciativa. Por ello, podemos encontrar casos en los que de verdad aparece combinado con intensificadores de grado, como sucede en el siguiente ejemplo, en el que antecede a muy.

(15) 23/2/2016, 17:21 - M2: Necesito dar una vuelta y despejarme

23/2/2016, 17:21 - M2: Estoy de verdad muy quemada

(Whatsapp, Corpus MEsA)

De hecho, este valor intensificador del decir afecta en muchos casos a la propia acción verbal, como sucede en los siguientes ejemplos:

(16) 2015/12/02, 14:04 - M1: Ya tenemos el yogur mas hipster

2015/12/02, 14:19 - H4: Los únicos lácteos que me gustan de verdad son los quesos, xD (Whatsapp, Corpus MEsA)

(17) Usuario 2 (hombre):

@ Usuario Pues no te van a tomar el pelo ni nada en esos restaurantes "de los caros" .... Porque yo he trabajado en restaurantes de 4 tenedores y si la gente supiera las cosas que piden lo que de verdad cuestan y lo que pagan a cambio seguro que pedian la hoja de reclamaciones.....pero nada nada...tu ve a esos restaurantes "de los caros".

(Páginas web, Corpus MEsA)

(18) «la medicación precisa para el cambio no es más agresiva que otras muchas que forman parte de lo que llamaríamos "lo cotidiano", lo que mata de verdad a los transexuales es el rechazo social»

(CORPES XXI, 2016) $)^{22}$

Como vemos, se trata de una función en la que de verdad funciona como intensificador de lo dicho, ligado a una parte del dictum. En nuestro corpus, lo encontramos afectando a adjetivos o a la propia acción verbal. En estos casos, actúa como operador de intensificación informativa y argumentativa. El locutor, a través de de verdad, se reafirma en su posición. El concepto de verdad se emplea, así, como marco para la argumentación, para legitimar y potenciar lo dicho. 


\subsection{De verdad como operador modal-enunciativo}

En algunos ejemplos, vemos cómo esta construcción, dentro de una misma intervención, además de actuar en el plano macroestructural de la enunciación, deriva también hacia el plano modal. En dichos ejemplos, encontramos una función intermedia en la que el valor enunciativo de de verdad se combina con el modal. En este uso, que también menciona Santos Río (2003), aparece acompañada por la complementación que más oración en indicativo y, por tanto, no presenta marginalidad sintáctica ni entonativa, sino que se encuentra integrada en el enunciado, a pesar de ser portadora de contenidos macroestructurales. En estos casos intermedios, de verdad es equivalente a es verdad que. Lo vemos a continuación:

(19)@usuario:

Si hay interés, de verdad que se nota...

(Twitter, Corpus MeSA)

(20) Usuario 5 (mujer):

Guapa tamara!!!!De verdad que me encantaría conocerte,un besazo enorme!!!

(Instagram, Corpus MeSA)

(21) Usuario 2 (mujer):

No puedo estar más de acuerdo, Luis. Ahora mismo tengo unos conocidos de luna de miel en Nepal que, cada vez que el wifi se lo permite, suben fotos a Facebook a diario. Es como si para disfrutar de lo que están viviendo necesitaran que todos sus contactos lo observaran. De verdad que es algo que todavía me cuesta comprender.

(Páginas web, Corpus MeSA)

En estos ejemplos, el locutor introduce esta expresión para reafirmarse en lo dicho y acentuar su compromiso asertivo. En estos casos intermedios entre la expresión de la enunciación y la modalidad, de verdad aparece acompañada por el que enunciativo. La distribución sintáctica es propia de muchos operadores modales, que sí pueden aparecer integrados en expresiones como: claro que, por supuesto que, etc. Sin embargo, dicha distribución sintáctica no funciona con operadores plenamente enunciativos como honestamente o sinceramente (*honestamente que; * sinceramente que). Además, estos operadores modales de confirmación, al igual que de verdad, pueden constituir un enunciado reactivo independiente, cosa que tampoco sucede con los operadores enunciativos. Esto supone un claro síntoma de que de verdad comienza a comportarse, en ciertos contextos, de manera análoga a un operador modal de confirmación.

Esta deriva hacia el plano modal llega a su culmen con los casos en los que de verdad funciona como expresión modal de confirmación en intervención reactiva y constituye un enunciado independiente que, a veces, ocupa enteramente la intervención. Teniendo en cuenta que se trata de un uso muy actual del que no hay noticia en ningún repertorio lexicográfico, nos interesamos especialmente por este en los apartados siguientes. 


\subsection{De verdad como operador modal}

En intervención reactiva, de verdad aparece en nuestro corpus ocupando el hueco funcional de un operador modal de confirmación al constituir la respuesta a un enunciado iniciativo asertivo, y no a una pregunta confirmativa, como sucedía en el ejemplo 12. En estos contextos, constituye un enunciado independiente y presenta un contenido procedimental, un significado unitario relacionado con la valoración subjetiva del hablante respecto a la intervención previa de otro interlocutor. Mediante su empleo, el locutor la evalúa como cierta y expresa que comparte su punto de vista. Dado que constituye un enunciado independiente, puede ocupar una intervención reactiva completa, como sucede en los siguientes casos, en los que aparece sola o acompañada únicamente de la transcripción del sonido onomatopéyico de la risa. El hecho de que aparezca solo nos muestra que los hablantes ya lo emplean y consideran como miembro del paradigma de expresiones de confirmación:

(22) 23/08/2017 3:04:30: M1: Y un párrafo que me gustó mucho fue este 23/08/2017 3:06:03: M1: <imagen omitida>

23/08/2017 3:13:40: H1: Ojala nos lo aplicasemos todos un poquito

23/08/2017 3:13:57: H1: Y lo disfrutasemos todo con mas conciencia

23/08/2017 3:14:21: M1: De verdad

(Whatsapp, Corpus MeSA)

(23) 04/09/2017, 23:01 - H1: como pued estar tan tremendo?

04/09/2017, 23:01 - M1: de verdad jajaj

(Whatsapp, Corpus MeSA)

(24) 04/11/2017 16:42:43: H1: que la gente caen 2 gotas y parece que es acido o algo 04/11/2017 16:43:10: M1: Jajaja de verdad (-70)

(Whatsapp, Corpus MeSA)

En el siguiente caso, el locutor emplea de verdad para expresar confirmación ante la realidad expuesta en la intervención previa que, en este caso, es la manifestación de una emoción negativa provocada por la distancia que separa a los hablantes y, a continuación, introduce otro enunciado en el que incide, de forma coorientada con la intervención anterior, en su insatisfacción ante el hecho presentado por el interlocutor:

(25) 31/01/2016 19:50:53: M1: Qué pena que no estés aquí y pueda verte cuando me apetezca $\odot$

31/01/2016 19:51:02: M1: De verdad, qué mierda

(Whatsapp, Corpus MeSA)

En el ejemplo siguiente de Instagram, la encontramos intensificada mediante el empleo de varios signos de exclamación, que es uno de los recursos más usuales en el discurso digital para intensificar (Sanmartín Sáez 2007), además de una interjección y de un comentario en el que valora positivamente lo dicho por el interlocutor. 
(26)@iberia:

Las proporciones no existen.

Existe la mirada, el objetivo de una cámara.

No es lo que fotografías.

Es el ojo con el que miras.

[Imagen del perfil de un avión en la pista de aterrizaje]

Usuario 46 (no identificado):

De verdad !!!! pfff así se hace

(Instagram, Corpus MeSA)

En este uso como operador modal, de verdad sirve al locutor para expresar al interlocutor que comparte su mismo punto de vista, es decir, funciona como un operador modal y ocupa el hueco funcional de estas unidades. De manera que, en contextos dialógicos reactivos, y cuando responde a una intervención iniciativa asertiva, nuestra construcción es conmutable por otros operadores modales que pueden constituir respuestas confirmativas como desde luego, efectivamente, exactamente, etc. Frente a estos, nuestra expresión, además de confirmar, introduce una valoración del locutor mediante la que califica lo dicho por el interlocutor como veraz. Nuestra expresión suele aparecer encabezando la intervención reactiva, aunque, en ocasiones aparece tras otras partículas modales: las interjecciones. Sucede en los ejemplos siguientes, en los que la expresión de confirmación aparece tras interjecciones que indican sorpresa:

(27) Usuario 40 (mujer):

[Mención al usuario 41] el que dice doraemos y después la play 1 es tu doble????

Diooos de perfil sois iguales :o :0:0

Usuario 40 (hombre):

Jajajajjajajajaka dios de verdad! Me parto XD XD XD XD XD XD XD XD

(Blog, Corpus MeSA)

(28) 19/11/2017 22:22:18: H1: Y no se puede ir detras de alguien que no quiere nada para ti 19/11/2017 22:23:27: M1: Ay, de verdad

(Whatsapp, Corpus MeSA)

(29)@usuario

También pensé algo similar pero se me hizo raro que solamente JungKook estuviera en el wonder y que hasta ahí le dejaran cuando el vídeo está lleno de teoría así que pineso que lo pueden retomar

Pero bueno espero pronto saber, por lo pronto a prepararse

[mención a usuario]

@usuario

Wow de verdad, muy cierto. A lo mejor Wonder lo vuelven a retomar.

(Twitter, Corpus MeSA)

En el ejemplo anterior, además, aparece combinada con otro operador de confirmación que expresa un contenido análogo. Por tanto, aunque puede aparecer solo y funcionar por sí mismo de un modo similar a un operador de confirmación, también puede aparecer combinado con otras expresiones que portan ese mismo contenido modal. La acumulación de estas expresiones modales tiene como consecuencia el énfasis y la focalización informativa. 
Por otra parte, es muy usual que de verdad aparezca introducido por el conector además. Sucede en muchos ejemplos en nuestro corpus. Mostramos algunos de ellos a continuación. En el primero de ellos, además de verdad constituye por sí sola la intervención reactiva, junto a la transcripción del sonido onomatopéyico de la risa. En los demás casos, nuestra construcción aparece seguida de otros enunciados coorientados con la intervención iniciativa previa:

(30) Usuario 3 (no identificado):

No te obsesiones...

Usuario 2 (no identificado):

...que sube el cortisol XD

Usuario 3 (no identificado):

Además de verdad jaja

(Foro, Corpus MeSA)

(31)@usuario

Tú y tus marionetas los más caraduras. Vas a pasar a la historia como el peor dirigente para policía municipal

(a) usuario

Además de verdad, matrícula de honor a la peor gestión .

Tic tac tic tac

(Twitter, Corpus MeSA)

(32)@usuario

Verdad verdadera

[Imagen con la siguiente frase: «No importa la edad que tengas, cuando vayas al médico tu madre hablará por ti».]

Usuario 108 (mujer):

Jajaja ademas de verdad mira mama [mención a usuario] las madres ablan mejor :-):

(Facebook, Corpus MEsA)

Aunque hemos encontrado en diversos casos de verdad antecedido por el conector además, no lo hemos encontrado ante otras expresiones que indiquen adición. Sin embargo, sí hemos documentado además de verdad introducido por la conjunción copulativa y en casos como los siguientes:

(33)@usuario:

Eran el Apocalipsis Friki de la época

@usuario:

Y además de verdad. Para muestra, un botón.

[Fotografía de los protagonistas de la serie Friends]

(Twitter, Corpus MEsA)

(34)@usuario:

[Imagen con el siguiente texto: vengarse de un muerto es una cobardía. Desenterrar a un muerto que pertenece a la historia es histerismo e impotencia. Y de hacerlo, el desenterrados, si es valiente, tiene que estar presenta en el acto siempre que pueda sostener la mirada vacía de la calavera." Napoleón Bonaparte] 
@usuario:

$Y$ además de verdad, bien dicho.

(Twitter, Corpus MEsA)

Además de verdad ${ }^{23}$ es más frecuente en nuestro corpus como expresión reactiva de confirmación frente a de verdad. De hecho, su alta frecuencia nos ha llevado a plantearnos la posibilidad de que la expresión reactiva fijada, en primer lugar, haya sido además de ver$d a d$, y a partir de esta, se esté empezando a emplear de verdad como intervención reactiva de confirmación por sí sola. Para comprobar nuestra hipótesis, hemos hecho una búsqueda en el corpus de conversaciones Val.Es.Co. 2.0., y en CORDE, CREA y CORPES XXI para tratar de averiguar cuándo de verdad y además de verdad comienzan a emplearse como intervención reactiva modal.

En CORDE solo encontramos un ejemplo de de verdad que data de $1972^{24}$ y aparece funcionado como enunciado reafirmativo independiente en discurso monológico. En él, aparece ante el adverbio además. La construcción aparece introducida por la conjunción copulativa $y$ :

(35) Y ya, como dijeron después los civiles, se llegó al desenfreno. A mí no me pregunte. Yo, cuando llegan los civiles, yo me callo. Y además de verdad. Buscaron, no sé dónde, una bacalada. Y se la jalaron a toda prisa.

(CORDE, 1972)

En CREA también encontramos un solo ejemplo de de verdad como intervención reactiva modal, de $1984^{25}$. En él, al igual que en el ejemplo anterior, también la encontramos precedida por y además. Este ejemplo constituye la primera documentación en la que nuestra construcción aparece como intervención reactiva. Como podemos ver, es una fecha bastante reciente, si consideramos la primera documentación de de verdad como operador enunciativo ${ }^{26}$ :

(36) -Era un chiste.

-Bueno está lo bueno.

-Y además de verdad.

-Señor, señor, qué cáliz.

(CREA, 1984)

En CORPES XXI no hemos encontrado ningún ejemplo en el que de verdad funcione como expresión reactiva de confirmación tras una intervención iniciativa asertiva ${ }^{27}$.

23 Barajamos la hipótesis de que la forma de verdad introducida por el conector además en intervención reactiva es más intensificada. Creemos que la combinación con estos marcadores incrementa el grado de aserción. Dicha hipótesis está siento comprobada en el proyecto "De construcciones periféricas a operadores discursivos: un estudio macrosintáctico del español actual".

24 El fragmento pertenece a la obra A traque barraque de Alonso Zamora Vicente.

25 Ejemplo hallado en La lucha inútil de Ramón Ayerra.

26 “Ny la pensáys?”

"No, de verdad, señor." (Crónica de Adramón, c1492).

27 Sí lo hemos encontrado como respuesta una pregunta confirmativa como vimos en el ejemplo 12. 
En el corpus Val.Es.Co. 2.0. encontramos, en total, dos ejemplos en los que nuestra construcción aparece como intervención reactiva de confirmación. Son los siguientes:

(37) A: mi abuela no se entera tía/ cuando vinieron Jose y todos estos al chalet/ eixos amiguets teus són molt simpàtics eh? / yo digo ni se le ocurra a nadie decir nada/ tía/ que s- que lo trabuca todo y no se entera de nada§

C: §¿tú eres el novioo? (RISAS)

A: (RISAS) además de verdad $\downarrow$ tía

(Corpus Val.Es.Co., 1994)

(38) H: sí pues ahora con los exámenes a ver quién coño sale§

F: $§$ HOStia! / además de verdad /// 1- la cosa tía $\uparrow$ es que quiero ver Los puentes de Madison $\uparrow / /$ y sólo queda ya e- sólo está en un cine tía y o me espabilo oo// ( ( )) no voy a ir a verla/ [por eso tampoco]

(Corpus Val.Es.Co., 1996)

Como podemos comprobar, la documentación más temprana del uso confirmativo reactivo de de verdad es del CREA (1984), seguida de los casos encontrados en el Corpus Val. Es.Co. (1994 y 1996). En todos los casos encontrados, de verdad aparece introducido por además. Aunque son pocos casos los encontrados, estos datos refuerzan nuestra hipótesis de que además de verdad surge como intervención reactiva de confirmación y que es a partir de esta surge la expresión reactiva de verdad.

En ninguna fuente, salvo en el Corpus MEsA, en el que se recoge discurso actual (desde 2007 hasta la actualidad) hemos encontrado ejemplos en los que de verdad constituya una expresión confirmativa por sí sola, lo cual nos indica que este empleo es sumamente reciente.

\subsubsection{Grado de fijación de de verdad como operador modal}

Si tomamos como referencia algunos rasgos que se consideran para describir el proceso de gramaticalización de un marcador ${ }^{28}$, tales como: la invariabilidad morfológica y sintáctica, la marginalidad, el contenido semántico procedimental, la función de guiar las inferencias que se han de obtener de los enunciados, etc. (Martín Zorraquino y Portolés 1999, Company 2004, Traugott, 2003), comprobamos que de verdad es un elemento fijado que constituye un operador. Por tanto, ha sufrido un proceso de subjetivización (Trauggot 1995) que ha hecho que el hablante imprima en esta expresión "su perspectiva o punto de vista personal respecto a las entidades objeto de la comunicación y respecto al enunciado o evento en general" (Company 2004: 24). De hecho, ya en los repertorios lexicográficos consultados, de verdad se recoge como un marcador que afecta a la enunciación y tiene usos modalizadores (Santos Río 2003, Fuentes Rodríguez 2009). Este nuevo uso como elemento modal de confirmación en intervención reactiva es el que no se recoge en dichos repertorios. Creemos que esta ausencia se debe a su carácter actual. En definitiva, aunque se trata de una

28 Existe una importante controversia bibliográfica en torno a la gramaticalización de marcadores del discurso, en la que se discuten sus rasgos específicos frente a otros procesos de gramaticalización y su direccionalidad, pero no trataremos este asunto aquí. Para ahondar en este tema, véase (Traugott 1995, Company 2008, Diewald 2011, entre otros.) 
expresión enunciativa que ha extendido su ámbito de actuación al plano modal, conserva el alto grado de fijación del operador enunciativo de verdad, ya que en posición reactiva tampoco encontramos casos en los que haya variabilidad morfológica, elementos insertos ni complementación alguna.

\section{CONCLUSIONES}

Como hemos tratado de mostrar en esta investigación, de verdad presenta varios usos: como construcción libre, como complemento periférico, como operador de intensificación, como operador enunciativo y como operador de confirmación, además del funcionamiento intermedio modal-enunciativo. En todos los usos, el locutor lo emplea para ponderar lo dicho, evocando los conceptos de veracidad y certeza que provienen del contenido léxico originario del núcleo verdad.

$\mathrm{Su}$ proceso evolutivo ha tenido lugar a través de la abstracción de la construcción de verdad, que pasa a expresar contenidos macroestructurales que hacen referencia al compromiso enunciativo del hablante y a su subjetividad. A través de un proceso de subjetivización, la expresión adquiere un significado procedimental, aunque ligado al propio concepto de veracidad. Como hemos podido comprobar, todas las etapas evolutivas de esta construcción coexisten en la actualidad, lo cual nos manifiesta su polifuncionalidad (Hummel 2012). Esta evolución puede resumirse del siguiente modo:

\begin{tabular}{|l|l|l|}
\hline \multicolumn{1}{|c|}{ Estadio 1 } & \multicolumn{1}{|c|}{ Estadio 2 } & \multicolumn{1}{c|}{ Estadio 3 } \\
\hline $\begin{array}{l}\text { De verdad como construcción } \\
\text { libre }\end{array}$ & $\begin{array}{l}\text { Complemento periférico ([te] lo } \\
\text { digo de verdad })\end{array}$ & $\begin{array}{l}\text { Operador: } \\
\text {-Intensificación } \\
\text {-Enunciación } \\
\text {-Modalidad }\end{array}$ \\
\hline
\end{tabular}

Tabla: Proceso evolutivo de de verdad ${ }^{29}$

El uso en el que más nos hemos detenido es en el que de verdad ocupa el hueco funcional de un operador modal de confirmación en intervención reactiva, ya que se trata de un uso que no se ha descrito en la bibliografía, dada su novedad. Como hemos visto, se trata de un empleo en el que de verdad constituye la respuesta confirmativa a una aserción previa, y no a una pregunta confirmativa. Frente a otros operadores de confirmación, como desde luego o absolutamente, nuestra expresión se emplea para realizar una evaluación positiva de la intervención previa a la que se refiere, la cual se relaciona con el concepto de verdad.

$\mathrm{Al}$ tratarse de una construcción ya fijada como operador enunciativo y reconocida como tal en la bibliografía correspondiente, se trata de una forma fijada sintáctica y morfológicamente. Sin embargo, ha extendido su uso y ha pasado a afectar no solo al plano macroestructural de la enunciación, sino también al modal.

La primera documentación como intervención reactiva de confirmación de de verdad a la que hemos accedido data de 1984; sin embargo, la primera documentación de de verdad como operador enunciativo la encontramos ya a finales del siglo XV. Esto nos muestra cómo

29 En términos de Traugott: Clause-internal Adverbial $>$ sentence adverbial $>$ discourse particle. 
el proceso de subjetivización llevó a la forma libre de verdad a expresar contenidos macroestructurales, en un primer momento, relacionados con la enunciación, y recientemente, también con la modalidad.

En numerosas ocasiones, hemos encontrado la forma de verdad antecedida por el adverbio además. Los resultados aportados por la búsqueda en CORDE, CREA, CORPES XXI y el Corpus Val.Es.Co. 2.0., aunque no son muy numerosos, parecen confirmar nuestra hipótesis de que la respuesta confirmativa además de verdad es previa a de verdad. De hecho, de verdad como expresión de confirmación solo aparece registrada en el Corpus MeSA, que es el corpus en el que recoge un discurso más actual.

Queremos destacar, por último, la relevancia que tienen para los lingüistas corpus conversacionales como el Corpus MeSA y el corpus de conversaciones Val.Es.Co. 2.0., ya que nos permiten acceder a usos actuales que de otro modo sería muy difícil documentar.

\section{REFERENCIAS BIBLIOGRÁFICAS}

Anscombre, J. C. y O. Ducrot (1983). L'argumentation dans la langue. Liège: Pierre-Mardaga.

Berrendoner, A. (2002). "Les deux syntaxes", Verbum, XXIV (1-2), pp. 23-36.

Berrendonner, A. (2003). "Eléments pour une macro-syntaxe. Actions communicative, types de clauses, structures périodiques". En Scarano, A. (ed.). Macro-syntax et pragmatique. L'analyse linguistique de l'oral. Roma: Bulzoni editore, pp. 93-109.

Blanche-Benveniste, C. (2002). "Macro-syntaxe et micro-syntaxe: les dispositifs de la rection verbale”. En Andersen, H. L. y H. Nølke (eds.). Macro-syntaxe et micro-sémantique: actes du colloque international d'Arhus, 17-19 mai 2001. Berne: Peter Lang, pp. 95-118.

Blanche-Benveniste, C. (2003). "La recouvrement de la syntaxe et de la macro- syntaxe". En Scarano, A. (dir). Macro-syntaxe et pragmatique. L'analyse linguistique de l'oral. Atti dell'Incontro Internazionale Dipartimento di Italianistica, Firenze 23-24 aprile 1999. Roma: Bulzoni Editore, pp. 53-75.

Brenes Peña, E. (2018). "Lo que yo te diga funciones discursivas y proceso de gramaticalización", CLAC, 71, pp. 63-82.

Briz Gómez, A. (1998). El español coloquial en la conversación: esbozo de pragmagramática. Barcelona: Ariel.

Briz Gómez, A., S. Pons Bordería y J. Portolés (coords.) (2008). Diccionario de partículas discursivas del español. [En línea] (enero-febrero 2019).

Brown, P. y S. Levinson (1987). Politeness. Some universals in language usage. Cambridge: Cambridge University Press.

Cabedo, A. y S. Pons Bordería (eds.). Corpus Val.Es.Co 2.0. Consultado online en http://www.valesco.es.

Company, C. (2004). “¿Gramaticalización o desgramaticalización? Reanálisis y subjetivización de verbos como marcadores discursivos en la historia del español", Revista de Filología Española, LXXXIII (1), pp. 29-66.

Company, C. (2008). "The directionality of grammaticalization in Spanish", Journal of Historical Pragmatics, 9 (2), pp. 200-224.

Diewald, G. (2011). "Pragmaticalization (Defined) as Grammaticalization of Discourse Functions", Linguistics, 49 (2), pp. 365-390.

Dostie, G. (2004). Pragmaticalisation et marqueurs discursifs. Analyse sémantique et traitement lexicographique. Bruxelles: De Boeck/Duculot.

Fuentes Rodríguez, C. (1995). "Polifonía y argumentación: los adverbios de verdad, certeza, seguridad y evidencia en español”, Lexis, vol. XIX, pp. 59-83.

Fuentes Rodríguez, C. (2000). Lingüistica Pragmática y Análisis del discurso. Madrid: Arco Libros. 
Fuentes Rodríguez, C. (2006). "Un acercamiento pragmático a la posición del adjetivo”. En Casado, M. et al. (eds.). Actas del I Simposio Internacional de Análisis del Discurso: lengua, cultura, valores. Madrid: Arco Libros, pp. 1293-1309.

Fuentes Rodríguez, C. (2007). Sintaxis del enunciado: los complementos periféricos. Madrid: Arco Libros.

Fuentes Rodríguez, C. (2008). "Operadores de intensificación del adjetivo: cantidad y evaluación”, Rilce, 24.1, pp. 1-24.

Fuentes Rodríguez, C. (2009). Diccionario de conectores y operadores del español. Madrid: Arco Libros.

Fuentes Rodríguez, C. (2012). "La verdad como estrategia de legitimación discursiva", Discurso y Sociedad, 6 (1), pp. 128-155.

Fuentes Rodríguez, C. (2013). "La gramática discursiva: niveles, unidades y planos de análisis", Cuadernos de AISPI, 2, pp. 9-30.

Fuentes Rodríguez, C. (2016). "Operadores discursivos: focalización, modalidad e intersubjetividad". En López Serena, A. et al. (coords.). El español a través del tiempo. Estudios ofrecidos a Rafael Cano Aguilar. Sevilla: Editorial Universidad de Sevilla, pp. 877-900.

Fuentes Rodríguez, C. (2017). "Macrosintaxis y lingüística pragmática", CLAC, 71, pp. 5-34.

González Sanz, M. (2017). "Verás: aproximación pragmático-discursiva”, CLAC, 71, pp. 83-98.

Koch, P. y W. Oesterreicher (1990 [2007]). Lengua hablada en la Romania: español, francés, italiano. Madrid: Gredos.

Hummel, M. (2012). Polifuncionalidad, polisemia y estrategia retórica. Los signos discursivos con base atributiva entre oralidad y escritura. Berlin/Boston: De Gruyter.

Lanero Rodríguez, M. C. (2018). “Argumentación y atenuación en construcciones del tipo No es por $X$, pero Y”, CLAC, 71, pp. 55-64.

Martín Zorraquino, M. A. y J. Portolés (1999). "Los marcadores del discurso". En Bosque, I. y V. Demonte (dirs.). Gramática descriptiva de la lengua española. Madrid: Espasa Calpe, pp. 4051-4213.

Narbona, A. (2000). "Sintaxis Coloquial”. En Alvar, M. (dir.). Introducción a la Lingüística Española. Barcelona: Ariel, pp. 463-478.

Narbona, A. (2015). Sintaxis del español coloquial. Sevilla: Universidad de Sevilla.

Padilla Herrada, M. S. (2017). "Formas de expresión de la modalidad confirmativa en WhatsApp", Pragmalingüística, 25, pp. 439-466.

Pons Bordería, S. (1998). “Oye y mira o los límites de la conexión”. En Martín Zorraquino, M. A. y E. Montolío Durán (eds.). Marcadores discursivos: teoría y práctica. Madrid: Arco Libros, pp. 213-228.

Proyecto MEsA (2017). Corpus MEsA. [Recurso electrónico]. Disponible en: [http:/grupo.us.es/grupoapl/otrosapartados.php?otro=10].

Real Academia Española: Banco de datos (CORDE) [en línea]. Corpus diacrónico del español. $<$ http://www.rae.es $>$ [octubre-diciembre 2018].

Real Academia Española: Banco de datos (CORPES) [en línea]. Corpus del español del siglo XXI. $<$ http://www.rae.es> [octubre-diciembre 2018].

Real Academia Española: Banco de datos (CREA) [en línea]. Corpus de referencia del español actual. $<$ http://www.rae.es> [octubre-diciembre 2018].

Rodríguez Ramalle, T. (2003). La gramática de los adverbios en "-mente" o cómo expresar maneras, opiniones y actitudes a través de la lengua. Madrid: Universidad Autónoma de Madrid.

Val.Es.Co. (2014). "Las unidades del discurso oral”, Estudios de Lingüistica del español, 35, pp. 13-73.

Sanmartín Sáez, J. (2007). El chat. La conversación tecnológica. Madrid: Arco Libros.

Santos Río, L. (2003). Diccionario de partículas. Salamanca: Luso-Española de Ediciones.

Serrano, M. (1997). "Marcadores discursivos en español: acerca de la verdad y pues", Boletín de Filología, 36, pp. 265-286. 
Traugott, E. (1995). "Subjectivication in grammaticalization", en D. Stein y S. Wright (eds.). Subjectivity and subjectication: linguistic perspectives. Cambridge: Cambridge University Press, pp. 31-54.

Traugott, E. (2003). "Constructions in grammaticalization”, en B. D. Joseph y R. D. Janda (eds.). The handbook of historical linguistics. Oxford: Blackwell, pp. 624-647.

Yus, F. (2001). Ciberpragmática: el uso del lenguaje en Internet. Barcelona: Ariel.

Yus, F. (2010). Ciberpragmática: nuevos usos del lenguaje en Internet. Barcelona: Ariel.

Yus, F. (2011). Cyberpragmatics. Internet-mediated communication in context. Amsterdam/Philadelphia: John Benjamins. 